\title{
An analysis of the type of community service investment project for the expansion of speech- language rehabilitation services in Korea
}

\author{
Kyung Jin Seo ${ }^{1}$, Eun Kyoung Lee ${ }^{1}$, Seong Hee Choi $^{2}$ \\ ${ }^{1}$ Department of Speech-Language Therapy, Dongshin University, Naju; ${ }^{2}$ Department of Audiology \& Speech-Language Pathology, Daegu Catholic \\ University, Gyeongsan, Korea
}

\begin{abstract}
Purpose: The purpose of this study is to analyze the type of provision of community service investment projects by method and scale of provision, to expand speech-language rehabilitation programs.

Methods: This study was conducted on 17 local governments that are implementing community service investment projects. The services of 17 local governments were categorized by method and scale of provision, their programs were analyzed, and services including speech-language pathologists were identified.
\end{abstract}

Results: When classifying the types of community service investment projects by delivery method, institutional-visited services accounted for the highest rate of $67.4 \%$. Of the 328 community service investment projects, 37 services (11.3\%) were provided by speech-language pathologists. Of the 223 institutional visit services, 22 (9.6\%) services included speech-language pathologists and speech-language related rehabilitation, and there were no home visit services. Regarding the scale, the highest portion (43.3\%) of the total 328 services was 'group type'. A total of 328 local community service investment projects were implemented by 17 local governments, 37 (11.3\%) of which were provided by speech-language pathologists. Among the community services provided by size, $23.1 \%$ of the services specified by speech-language rehabilitation and/or speech-language pathologists were provided.

Conclusions: The speech-language rehabilitation services were biased toward 'individual' and complex services, and the proportion of 'group type' services was very small. Accordingly, speech-language rehabilitation services should expand the scope of speech-language rehabilitation services at the 'group type' scale nationwide. In addition, delivery methods should be diverse by providing new services in the post-Corona era.

Keywords: Community social service investment, Speech-language rehabilitation, Speechlanguage pathologist, Corona-19, Post-corona era, Non-face-to-face remote guidance provision method

\section{INTRODUCTION}

The community service investment project is a service that is provided to those who need benefits such as language, psychology, art, etc. throughout their lives, and provides various services to various subjects, including farming and fishing areas, multicultural families, grandparents, and underprivileged families from infants to the elderly.

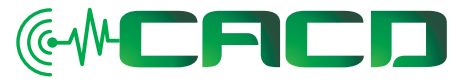

Received: April 10, 2021 Revision: April 20, 2021 Accepted: April 20, 2021

\section{Correspondence: Eun Kyoung Lee}

Department of Speech-Language Therapy, Dongshin University, 67 Dongshin University, Dongshin Dae-gil, Naju 58245, Korea

Tel: +82-61-330-3473

Fax: +82-61-330-3476

E-mail: eklee@dsu.ac.kr
(C) 2021 The Korean Association of SpeechLanguage Pathologists

This is an Open Access article distributed under the terms of the Creative Commons Attribution NonCommercial License (https://creativecommons.org/ licenses/by-nc/4.0/) which permits unrestricted noncommercial use, distribution, and reproduction in any medium, provided the original work is properly cited. 
The community service investment project aims to resolve the welfare blind spot, revitalize the social service market, and create new jobs through the development of local customized social services.

Accordingly, The Ministry of Health and Welfare's major policy direction for 2021 of the community service investment project includes reinforcing education and consulting support to promote participation in social and economic organizations related to the development and operation of new services [1].

In this regard, the community service investment project needs to open a program that reflects the needs of the service target and develop a form of provision convenient for the target.

Since 2017, while the number of users and budget has decreased, the number of providers and personnel has increased. Especially when the distribution of providers has begun to show problems that are not balanced [2-4].

Among these services, speech-language rehabilitation pathologists are categorized into 'Child and Adolescent Psychological Support Service', and 'Infant Development Support Service,' 'Adaptation Support Service for Children from Multicultural Families.' Programs such as 'Child and Adolescent Vision Formation Support Service,' which must include speechlanguage rehabilitation personnel, 'Visiting Happy Families Visiting Service,' 'Service Underprivileged Family Integrated Case Management Service,' and 'Customized Health Promotion Service for People with Disabilities at Home', etc. In the case of services targeting families of vulnerable social groups, however, speech-language pathologists are not included in the provision of human resources.

In reality, multicultural families and low-income families are exposed to poor physical environments and are in a poor environment where social communication skills may be difficult, which is a threat to speech-language development [5-7].

Nevertheless, speech-language pathologists are not included in the services for them [8].

In addition, despite the fact that there are many community service programs for the elderly, speech-language rehabilitation and language communication services are insufficient.

However, the prevalence rate of dementia, which the elderly are most concerned about, is $9.8 \%$ among the elderly population in Korea.

Although dementia is a disease caused by aging, which is a typical problem of verbal and cognitive memory degeneration, there is no specialized program to prevent the degenera- tion of their speech function and to solve the problem of communication [9].

In particular, even though most of the elderly can receive 'Customized Dementia Prevention Services', speech-language pathologists are not included in the personnel who can provide this service.

In the case of dementia patients, it is necessary to activate patient-centered treatment and consistent home visit service to improve the ability to perform daily life and cognitive function necessary for daily life $[10,11]$.

Consultation and rehabilitation services for community service investment projects are known to lack the supply of the provision personnel more than other types of services, and those with national certificates are lower than those with private certificates [12].

In speech-language rehabilitation, 1:1 service between the speech-language pathologist and the target person is also important, but it is also important that the target person's family members participate in the rehabilitation service together.

In particular, when children and adolescents receive speech-language rehabilitation services, home speech-language intervention is very helpful in improving their linguistic mutual ability $[13,14]$.

Also, in speech-language rehabilitation services, group therapy provides qualitative services that are separate from 1:1 services in terms of high efficiency, economy, performance, etc. to those target people to various disabilities and developmental delays [15].

Among a total of 328 resident service investment projects conducted by 17 local governments, 33 (10.2\%) services included speech-language pathologists with national qualifications as among the personnel.

Although speech-language and communication programs can be provided for all ages, the service targets of the consumer-centered community service investment project are not provided with specialized speech-language rehabilitation and services to improve communication [8].

In addition, it is necessary to establish a system that can continuously check the distribution of resources supplying social services and periodically monitor the status of providers and personnel [16].

The financial and administrative capabilities of local governments are important for revitalization of community service investment projects, and local governments must continuously reorganize existing projects that are being provided to target audiences [17]. 
Coronavirus Infectious Disease-19 (2019 novel coronavirus, hereafter COVID-19), which started at the end of 2019, has a direct physical and mental impact not only on communities and schools, but also on children and adolescents in the developmental period of growth [18].

Due to the quarantine guidelines, such as mandatory wearing of masks, restrictions on group activities, distancing, restrictions on outdoor activities, and refraining from conversation, students were subject to many restrictions in learning, physical activities, and social relations [19].

Currently, most of the community investment service projects are centered on institutional visits and visits to experience centers, and activities are being restricted in many service areas due to the quarantine guidelines of COVID-19. Therefore, in order to efficiently operate programs that reflect various social situations, this study considers the actual situation based on the standard information for the community service investment project currently operated by local governments, focusing on the program provision method and scale, and by grasping the degree of participation in the project by speechlanguage pathologist provision method and provision scale. For this purpose, community service investment projects by method of provision and scale of provision were categorized, and found out the degree to which speech-language pathologists are designated as provision personnel. Based on this, the aim is to expand programs to improve the speech-language and communication of community service investment projects, improve service provision in compliance with the COVID-19 quarantine guidelines, and propose guidelines for the provision of services in the post-corona era.

\section{METHODS}

\section{Research subject}

This study was conducted on 17 local governments that are carrying out investment projects for community service. The 17 cities and counties are Gangwon-do, Gyeonggi-do, Gyeongsangnam-do, Gyeongsangbuk-do, Gwangju, Daegu, Daejeon, Busan, Seoul, Sejong Special Self-Governing City, Ulsan, Incheon, Jeollanam-do, Jeollabuk-do, Jeju Special SelfGoverning Province, Chungcheongnam-do, and Chungcheongbuk-do.

A total of 328 community service investment projects implemented in 17 local governments were analyzed by method of provision and scale of provision, the programs were analyzed, and services including speech-language pathologists were identified.

In the preceding study, among the community service investment projects undertaken by 17 local governments, the purpose and contents of the programs are the same, but programs that are subdivided according to unit price and type of provision were integrated and classified into a total of 316 .

However, in this study, the unit price and the form of provision vary according to the detailed programs of the community service investment projects implemented by 17 local governments, so the detailed programs were not integrated and classified into a total of 328 .

Depending on the method of provision, the community service investment project was classified into three areas: an institutional visit type, a home visit type, and a complex type of institutional/home visit type.

Institutional visits, group activities, and experiential site visit services were classified as 'Institutional Visit Type', inhome visits were classified as 'Home Visit Type', and services available for both institutional and home-based visits were classified as 'Complex Type'.

At this time, 'Group Activities' and 'Experiential Site Visits' were classified into 'Institutional Visits Type' by separating them from home-based visits according to the provision method of providing visits to other institutions because the institutions that visit were different depending on the program.

The community service investment projects were classified into three types: 'Individual Type,' 'Group Type', and 'Complex Type' of individual/group provision according to the scale of provision.

The scale of provision is 'Individual Type' when 1:1 service is provided, 'Group Type' when a 1:2 or more services were provided, and 'Complex Type' when service is provided individually and collectively, based on the provision scale specified in the guidelines for each of the 17 local governments.

In addition, the services including speech-language pathologists were classified and analyzed by the method and scale of provision in the community service investment project.

The analysis criteria were modified and supplemented by Kim and Lee (2017).

\section{Data collection and analysis method}

Data was collected on the basis of the performance standards of community service investment projects provided by the social service support groups of 17 local governments, and the services implemented by each local government were classi- 
fied and analyzed by the method of provision and the scale of provision.

In addition, the services specified in the personnel provided by speech-language pathologists were extracted from the personnel providing each service, and compared with the total number of services, the frequency and percentage were analyzed.

\section{Result processing}

A program that includes pathologists and speech-language therapy among the total programs by analyzing investment projects for community service investment by method of provision and size of provision and analyzing them by frequency and percentage, and extracting programs that include speech rehabilitation and speech therapists by method of provision and scale of provision. And the number of were analyzed by frequency and percentage.

\section{RESULTS}

\section{Current status of investment projects for community service by method of provision}

In order to find out the operational status of the community service investment project by provision method, the provision method was classified into institutional visit type, home visit type, and complex type.

Of the total of 328 services, institution visit type services accounted for the highest rate at $221(67.4 \%)$, followed by complex type services using both methods with 81 (24.7\%), while home visit type services accounted for 26 (7.9\%) (Figure 1).

Looking at the method of providing community service investment projects, it was found that services were provided in order of institutional visit type, complex type, and home visit type.

Currently, the institutional visit service type has the highest rate, but the rate of home visit service type is low.

The results of the analysis of the current status of service provision by the provision method of community service investment projects implemented by 17 local governments are shown in Table 1.

Of the 328 community service investment projects, the number of services included as personnel provided by speech-language pathologists was 37 , accounting for $11.3 \%$.

If the services including speech-language pathologists are classified according to the method of provision, out of 81 complex services, 15 services including speech-language pa-

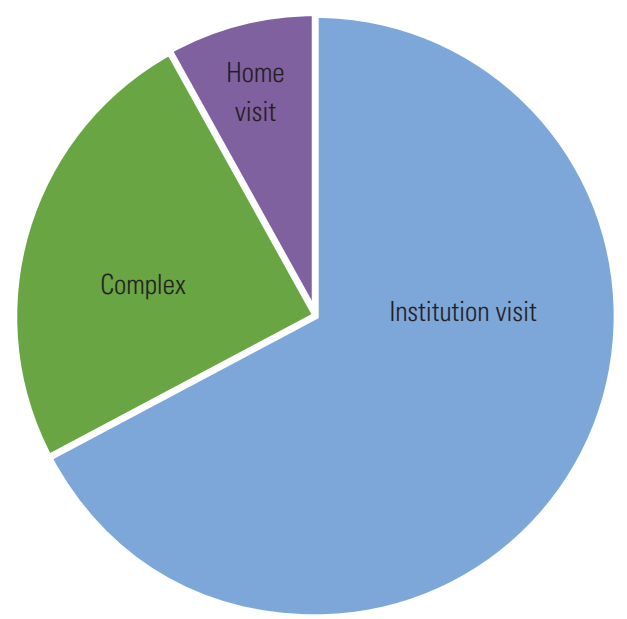

Figure 1. Types of community service investment projects in Korea.

thologists and speech-language therapists as provision personnel accounted for $18.5 \%$.

Of the 221 institutional visit type service, 22 services including speech-language pathologists and speech-language therapists accounted for $9.6 \%$ of them, and there were no home visit type services.

As a result of the 17 local governments' resident service investment projects, Gyeonggi Province was confirmed to be "My Children's Psychological Support Service-1," “My Children's Psychological Support Service-2," and Daejeon City, Gyeongsangnam-do Province, and Seoul provided 'Child and Youth Psychological Support Service'.

In the case of Gyeongsangbuk-do, there was 'Infant Development Support Service,' and in Gwangju Metropolitan City, there was 'Child and Adolescent Psychological Support Service' and 'Gwangju-type Infant Development Support Service' In Daejeon, there were 'Children and Youth Psychological Support Service.'

In the case of Busan Metropolitan City, there was a 'Child and Adolescent Psychological Healing Service (My Child has Changed)'

Ulsan Metropolitan City, Jeollanam-do, and Chungcheongbuk-do had 'Infant Development Support Service' and 'Child and Adolescent Psychological Support Service.'

Incheon Metropolitan City had a 'Child and Adolescent Psychological Support Service' and a 'Peer Class for Social Enhancement'.

In Jeollabuk-do, there were 'Child and Adolescent Psychological Support Services' and 'Food Therapy for Youth'

In South Chungcheong Province, there were 'Child and Ad- 
Table 1. Current status of investment projects for community service by method of provision

\begin{tabular}{|c|c|c|c|c|c|c|c|c|}
\hline \multirow[b]{2}{*}{ Regio } & \multicolumn{2}{|c|}{$\begin{array}{l}\text { Institutional } \\
\text { visit }\end{array}$} & \multicolumn{2}{|c|}{$\begin{array}{l}\text { Home } \\
\text { visit }\end{array}$} & \multicolumn{2}{|c|}{ Complex } & \multicolumn{2}{|c|}{ Total } \\
\hline & A & $B$ & $A$ & B & $A$ & $B$ & A & B \\
\hline Gangwon & 13 & - & 2 & - & 5 & 1 & 20 & 1 \\
\hline Gyeonggi & 19 & 2 & - & - & 2 & 1 & 21 & 3 \\
\hline Gyeongsangnam & 11 & 1 & - & - & 5 & 2 & 16 & 3 \\
\hline Gyeongsangbuk & 10 & 1 & - & - & 6 & 2 & 16 & 3 \\
\hline Gwangju & 13 & 2 & 2 & - & 5 & - & 20 & 2 \\
\hline Daegu & 11 & 1 & - & - & 3 & - & 14 & 1 \\
\hline Daejeon & 17 & 1 & 2 & - & 5 & 1 & 24 & 2 \\
\hline Busan & 7 & 1 & 1 & - & 7 & - & 15 & 1 \\
\hline Seoul & 10 & 1 & 1 & - & 6 & 1 & 17 & 2 \\
\hline Sejong & 4 & - & - & - & 3 & 1 & 7 & 1 \\
\hline Ulsan & 9 & 2 & 1 & - & 4 & - & 14 & 2 \\
\hline Incheon & 20 & 2 & 5 & - & 2 & - & 27 & 2 \\
\hline Jeollanam & 17 & 2 & 6 & - & 7 & - & 30 & 2 \\
\hline Jeollabuk & 21 & 2 & 2 & - & 6 & 2 & 29 & 4 \\
\hline Jeju & 10 & - & - & - & 7 & 3 & 17 & 3 \\
\hline Chungcheongnam & 16 & 2 & 4 & - & 5 & - & 25 & 2 \\
\hline Chungcheongbuk & 13 & 2 & - & - & 3 & 1 & 16 & 3 \\
\hline Total & 221 & 22 & 26 & 0 & 81 & 15 & 328 & 37 \\
\hline
\end{tabular}

A, Total service; B, Speech-language rehabilitation related service.

olescent Psychological Support Services' and 'Psychological Support Services for Families with Disabilities'

There was no service specified by speech-language pathologists as providing personnel in the institutional home visit type provision of community service investment projects in Gangwon-do, Sejong Special Self-Governing City, and Jeju Special Self-Governing Province.

Out of 328 services, speech-language rehabilitation services were not included among the 26 home visit type services.

As such, the community service investment project provides services in three areas: institutional visit type, home visit type, and institution/home visit type, but speech-language rehabilitation service is biased toward the institutional visit type and complex type service provision methods. There is no program for providing services in the home visit type of provision, and speech-language rehabilitation is limited to institutional visits, although speech-language rehabilitation is provided for the purpose of improving speech-language and communication problems to target persons in various communication environments.
As a result of this analysis, it was found that the opportunities for the beneficiaries of speech-language rehabilitation services to receive services in various communication environments are very limited.

This indicates that speech-language rehabilitation services are not provided to services targeting family factors, which are the main environmental factors in speech-language development and communication development, and thus the subjects are not provided with services in various communication environments.

In addition, it was found that due to COVID-19, the provision of face-to-face services through institutional visits is not smooth, so that children and adolescents may be in a blind spot where they do not get opportunities to promote development.

In such a national disaster situation, it is necessary to prepare guidelines for the development and operation of new services with a new method of providing non-face-to-face remote guidance and parental coaching in order to provide smooth service to those in the blind spot.

The results of analyzing the current status of speech-language pathologists among the provision of services by method of providing community service investment projects implemented by 17 local governments are shown in Table 1 .

\section{Current status of investment projects for community service by scale of provision}

In order to find out the operational status of the community service investment project by service scale, the service scale was classified into three types: 'individual type,' 'group type', and 'complex type'.

Out of a total of 328 services, the highest proportion of services was 'group type' with 142 (43.3\%), followed by 'complex type' with 104 (31.7\%), and 'individual type' with 82 (25\%) (Figure 2).

As a result of categorizing the community service investment project into three areas according to the scale of provision, it was found that the proportion of 'complex type' and 'group type' service provision is relatively small, and the proportion of 'individual type' service provision is relatively small.

The results of the analysis of the current status of service operation by the scale of the provision of community service investment projects implemented by the 17 local governments are shown in Table 2.

A total of 328 services of community service investment 


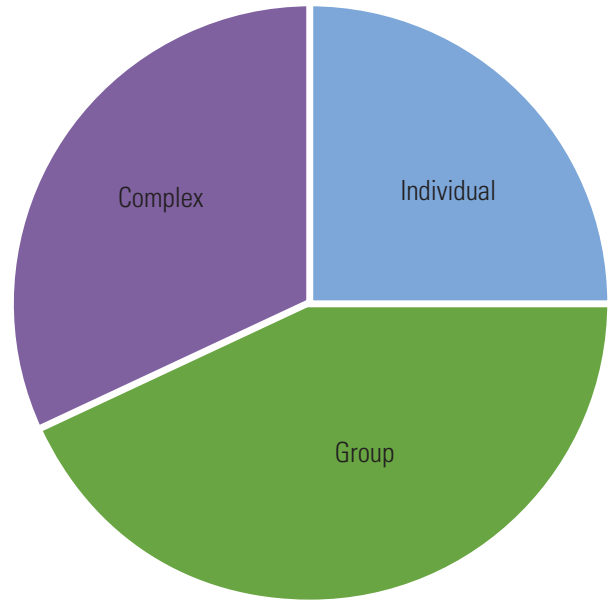

Figure 2. Operational status of community service investment projects by scale.

projects were provided, with 37 services including speechlanguage pathologists as personnel, accounting for $11.3 \%$.

According to the operation status of the community service investment project by size, 24 "complex" out of 328 services were designated as speech pathologists, $23.1 \%$ were provided by speech therapists, and 8 out of 82 services (9.8\%) were "personal". Group type services were 3.5\% out of 142 .

Looking at the scale of community service investment projects conducted by the 17 local governments, the services specified by speech-language pathologists in the 'group type' include 'Infant Development Support Service' in Gyeongsangbuk-do, Jeju Special Self-Governing Province, and Chungcheongbuk-do. 'Infant Development Support Service' and 'Food Therapy for Youth' in Jeollabuk-do.

In the 'group type' of community service investment projects in Gangwon-do, Gyeonggi-do, Gyeongsangnam-do, Gwangju, Daegu, Daegeon, Busan, Seoul, Sejong Special SelfGoverning City, Ulsan, Incheon, Jeollanam-do, and Chungcheongnam-do, there was no service designated as a human resource for speech-language pathologists.

As such, community service investment projects offer services in three areas: 'Individual Type,' 'Group Type' and 'Complex Type', but speech-language rehabilitation services are biased toward 'individual type' and 'complex type' services, and the proportion of 'group type' services is very small.

As a result of this analysis, it was found that the subjects provided with speech-language rehabilitation services were receiving services in a limited communication environment centered on individual guidance, as opposed to the communication environment in real life.
Table 2. Current status of investment projects for community service by scale of provision

\begin{tabular}{|c|c|c|c|c|c|c|c|c|}
\hline \multirow[b]{2}{*}{ Regio } & \multicolumn{2}{|c|}{$\begin{array}{l}\text { Individual } \\
\text { type }\end{array}$} & \multicolumn{2}{|c|}{$\begin{array}{l}\text { Group } \\
\text { type }\end{array}$} & \multicolumn{2}{|c|}{$\begin{array}{c}\text { Complex } \\
\text { type }\end{array}$} & \multicolumn{2}{|c|}{ Total } \\
\hline & $A$ & B & A & B & $A$ & B & A & B \\
\hline Gangwon & 5 & 1 & 10 & - & 5 & - & 20 & 1 \\
\hline Gyeonggi & 6 & - & 9 & - & 6 & 3 & 21 & 3 \\
\hline Gyeongsangnam & 6 & 1 & 6 & - & 4 & 2 & 16 & 3 \\
\hline Gyeongsangbuk & 4 & - & 8 & 1 & 4 & 2 & 16 & 3 \\
\hline Gwangju & 4 & 1 & 15 & - & 1 & 1 & 20 & 2 \\
\hline Daegu & 3 & 1 & 9 & - & 2 & - & 14 & 1 \\
\hline Daejeon & 3 & - & 11 & - & 10 & 2 & 24 & 2 \\
\hline Busan & 3 & - & 5 & - & 7 & 1 & 15 & 1 \\
\hline Seoul & 6 & - & 4 & - & 7 & 2 & 17 & 2 \\
\hline Sejong & 1 & - & 4 & - & 2 & 1 & 7 & 1 \\
\hline Ulsan & 2 & - & 2 & - & 10 & 2 & 14 & 2 \\
\hline Incheon & 9 & - & 9 & - & 9 & 2 & 27 & 2 \\
\hline Jeollanam & 6 & - & 16 & - & 8 & 2 & 30 & 2 \\
\hline Jeollabuk & 4 & - & 16 & 2 & 9 & 2 & 29 & 4 \\
\hline Jeju & 6 & 2 & 9 & 1 & 2 & - & 17 & 3 \\
\hline Chungcheongnam & 9 & 2 & 3 & - & 13 & - & 25 & 2 \\
\hline Chungcheongbuk & 5 & - & 6 & 1 & 5 & 2 & 16 & 3 \\
\hline Total & 82 & 8 & 142 & 5 & 104 & 24 & 328 & 37 \\
\hline
\end{tabular}

A, total service; $B$, Speech-language rehabilitation related service.

Children, adolescents, young people, and the elderly develop through interactions with others in social situations and perform social roles through occupations.

Speech-language rehabilitation has to provide speech-language and communication services to target subjects in various group environments and social situations, but the group scale of service provision is limited to individuals.

In such a limited supply scale situation, the provision of services for group activities has become more difficult due to the national disaster situation of COVID-19.

Group activities using non-face-to-face remote services for the development of speech-language and communication in social situations of subjects who need to live their lives through exchanges with others in limited communication situations comply with the COVID-19 quarantine guidelines and provide. It is a way to provide high quality service.

In addition, in preparation for the post-corona era, it is necessary to expand the provision of 'group type' services in local governments nationwide in advance.

The results of the analysis of the current status of service 
provision and speech-language pathologists by scale of community service investment projects implemented by the 17 local governments are shown in Table 2.

\section{DISCUSSION AND CONCLUSIONS}

This study analyzed community service investment projects by service method and scale, and developed a policy design and model to increase the proportion of programs needed by speech-language pathologists in real life and expand speechlanguage and communication services.

The conclusions according to this purpose are as follows.

First, looking at the service operation by community service investment projects method, we can see that the service is provided in three areas: an institutional visit type, a home visit type, and a mixed type of institutional/home visit type. But it is biased toward institutional visit type and the home visit type service method is insufficient.

In addition, when the proportion of speech-language rehabilitation by community service investment projects was classified, the service provision area of speech-language pathologists was concentrated in the institutional visit provision method, and the home visit provision method and the complex type service are insufficient.

According to Lee et al. [8], when categorizing community service investment projects by subject, considering that the service provision area of speech-language pathologist was concentrated among children and adolescents, it would be important to provide services to parents and families in the way of providing home visits.

However, the result that there are no visiting services that include speech-language pathologists means that children and adolescents, the largest service use group, do not receive quality services due to discrepancies in service areas and methods.

Second, when classifying the service operation by scale of community service investment business, three areas are 'individual type,' 'group type' and 'complex type', but they are biased towards 'complex type' and 'group type' service, and the 'individual type' service is insufficient.

In addition, looking at the proportion of speech-language rehabilitation by scale of community service investment projects, it was seen that speech-language pathologists were biased toward 'individual type' and 'complex type' services and 'group type' services were insufficient.

As such, the classification of community service investment projects by the scale of the provision showed that the overall service provided by speech-language pathologists was inconsistent.

This means that the scale of provision of community service projects is not balanced or homogeneous across each service area.

Based on the conclusions of this study, the following suggestions are made.

First, it is necessary to expand the service delivery area of speech-language pathologists by method of provision.

It is considered appropriate for those who benefit from speech-language and communication programs to receive balanced services in all ways of providing institutional visit type, home visit type, and experiential site visit type.

In addition, considering the large number of service groups for children and adolescents, it is necessary to expand the method of providing the home visiting type so that family members can participate as partners in speech-language rehabilitation services.

In particular, the 17 local governments across the country do not have a method of continuous home visit type provision in speech-language rehabilitation services, so it is essential to expand speech-language rehabilitation services centered on home visit type services nationwide.

Speech-language and communication is an expression that develops throughout a person's entire life.

Therefore, it is considered necessary to expand speech-language and communication programs aimed at preventing developmental delays and promoting communication, not just for disability-oriented treatment.

Speech-language and communication programs aimed at preventing developmental delays and facilitating communication differ in the quality of life of the beneficiaries of the service depending on the participation of family members, so policies are needed to expand the service.

Second, it is necessary to expand the service provision area of speech-language pathologists by scale of provision.

Out of 328 services provided by 17 local governments across the country, only 5 of them were once in which beneficiaries of speech-language and communication rehabilitation programs could receive services on a 'group type' scale, provided by 4 local governments: Gungsangbuk-do Province, Jeollabukdo Province, Jeju Special Self-Governing Province and Chungcheongbuk-do.

Since beneficiaries of speech-language and communication rehabilitation programs are provided with homogeneous 
and unbalanced services depending on the region, it is essential to expand the scope of speech-language rehabilitation services at the 'group type' scale nationwide.

Third, it is necessary to prepare guidelines for the development and operation of new services for non-face-to-face remote guidance, a new method of provision in preparation for the situation of COVID-19 and the post-corona era.

Due to COVID-19 and compliance with the quarantine guidelines, there is a limit to the provision of face-to-face services through institutional visits, so children, adolescents, adults, and senior citizens are not receiving opportunities for smooth development promotion and communication support.

There is a need to improve the quality of service provision by providing a new service linking coaching to parents and family members through non-face-to-face remote guidance to those in blind spots without receiving the benefits of the speech-language and communication rehabilitation program.

It is proposed to develop a non-face-to-face remote guidance provision method as a new service among the provision of community service investment projects and to prepare operational guidelines.

\section{REFERENCES}

1. Ministry of Health and Welfare. Community service investment project guide. 2021.

2. Ahn SR. The Status of Management of Social Service Agencies Providing e-Vouchers. KIHASA. 2020;10:36-50.

3. Jeon YH, Kim YD. A study of local governments' evaluation of the marketization of social service: focusing on the registration system of community social service investment. Health and Social Welfare Review. 2018;38:521-554.

4. Ham YJ. Social service area gap and mitigation measures. The Korean Association for Policy Studies. 2018;0:699-714

5. Kim YR, Kim YT. Linguistic performance of Korean children from low SES multicultural families. Journal of Speech-Language \& Hearing Disorders. 2011;7:73-88.

6. Kim HK, Pae SY, Yoon HJ. Decoding and reading fluency for children from low-income families. Journal of Speech \& Hearing Dis- orders. 2013;22:55-68.

7. Park SG, Cho JR, Park SH. Comparisons of Korean literacy and cognitive-linguistic skills among preschool children from rural and urban communities and multicultural families. Journal of Speech \& Hearing Disorders. 2014;23:33-46.

8. Lee EK, Lee MS, Jeong GH, Kim TW. Analysis on the actual condition of speech-language rehabilitation provision for the community social service investment projects: focused on targeting 17 cities nationwide. Clinical Archives of Communication Disorders. 2020;5:172-179.

9. Shin JW, Han HK, Shin SH, Park CH, Kim HJ, Kim DI. Analysis of the current status of dementia rehabilitation in Busan, South Korea. PNF and Movement. 2020;18:275-286.

10. Hwang YJ, Jung WM. Effects of a home environmental skill-building program on dementia patients based on community: Evidence based practice (a single subject research design). Journal of Society of Occupational Therapy for the Aged and Dementia. 2009;3:45-57.

11. Lee JH. The effect of shelter of dementia on cognitive function and depression level in elderly people in community. The Journal of Occupational Therapy for the Aged and Dementia. 2016;10:1-9.

12. Kim EJ, Kim YR. The working condition of social service workforce: focusing on the differences in social service type and regional scale. 2017;26:51-79.

13. Lee EK. The effect of language communication ability of home language intervention in parents for their children with cochlear implant. KSHA. 2008;17:155-169.

14. Ha SH. The effect of a language intervention program through parental training for young children with cleft palate. KSHA. 2013;22: 189-212.

15. Bae JA. Understanding and application of group therapy. Audiology and Speech Research. 2007;3:17-23.

16. Ham YJ. Regional disparities in social service provision. KIHASA. 2019;4:8-17.

17. Shin GH, Moon SM. The revitalization of community service investment projects a study on the impact: focusing on local government and community capabilities. Modern society and Administration. 2017;27:51-78.

18. Choi JY. The effects of COVID-19 pandemic on the mental health of the general public and children and adolescents and supporting measures. Journal of Korean Neuropsychiatric Association. 2021;60:2-10.

19. UNICEF. Don't let children be the hidden victims of COVID-19 pandemic. 2020. 